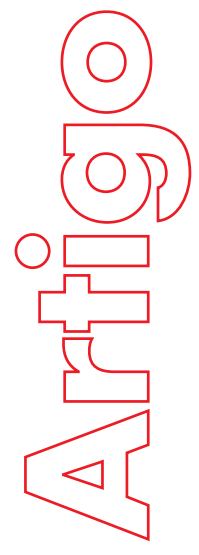

\title{
UTILIZAÇÃO DE DADOS POPULACIONAIS CENSITÁRIOS E DE IMAGENS DE SENSORES REMOTOS NO ESTUDO DA EVOLUÇÃO DA OCUPAÇÃO EM CANABRAVA E ENTORNO, SALVADOR, BAHIA, BRASIL, DE 1991 A 2010
}

\section{Eudoxio Antonio Batista Junior \\ Patrícia Lustosa Brito Anderson Dias de Freitas}

p. $49-72$

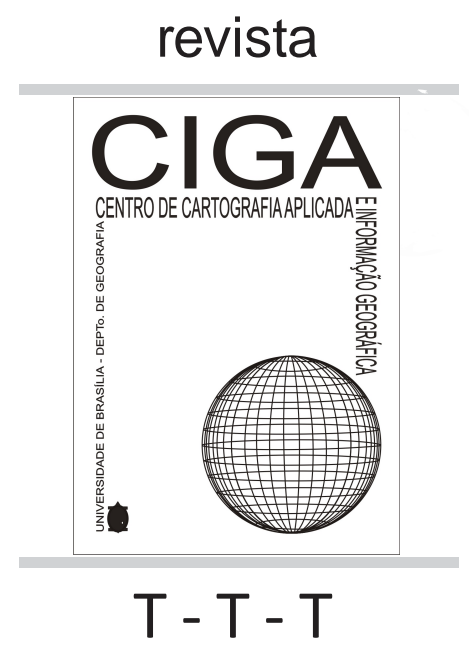

Revista Eletrônica:

Tempo - Técnica - Território,

V.6, N.1 (2015), 49;72

ISSN : 2177-4366

DOI: https://

doi.org/10.26512/

ciga.v6i1.20912
Como citar este artigo:

JUNIOR, E. A. B. Utilização De Dados Populacionais Censitários E De Imagens

De Sensores Remotos No Estudo Da Evolução Da Ocupação Em Canabrāava E

Entorno, Salvador, Bahia, Brasil, De 1991 A 2010. Revista Eletrônica: Tempo - Técnica - Território, v.6, n.1 (2015), p. 49:72 ISSN: 2177-4366.

DOI: https://doi.org/10.26512/ciga.v6i1.20912

Disponível em: http://periodicos.unb.br/index.php/ciga/

Este obra está licenciado com uma Licença Creative Commons

Atribuição-Não Comercial 4.0 Internacional. 


\title{
UTILIZAÇÃO DE DADOS POPULACIONAIS CENSITÁRIOS E DE IMAGENS DE SENSORES REMOTOS NO ESTUDO DA EVOLUÇÃO DA OCUPAÇÃO EM CANABRAVA E ENTORNO, SALVADOR, BAHIA, BRASIL, DE 1991 A 2010
}

\author{
Eudoxio Antonio Batista Junior \\ Mestre em Engenharia Ambiental Urbana pela UFBA, Geógrafo do Ministério da Agricultura, \\ Pecuária e Abastecimento - Mapa \\ Email: eudoxioabjr@yahoo.com.br
}

\section{Patrícia Lustosa Brito}

Doutora na área de Informações Espaciais pela USP, Professora da Universidade Federal da Bahia UFBA

Email: patricia.brito@ufba.br

\author{
Anderson Dias de Freitas \\ Graduando em Engenharia de Agrimensura e Cartográfica pela UFBA \\ Email: anders.freitas@yahoo.com.br
}

RESUMO: A expansão urbana vem ocorrendo de forma intensa nas últimas décadas nas grandes cidades brasileiras, ocasionando aumento da demanda por infraestrutura urbana, serviços e novas áreas para construção. O tema central deste artigo é analisar as características da expansão urbana na comunidade de Canabrava e seu entorno, em Salvador, Bahia, Brasil, com uso de dados censitários do IBGE dos anos de 1991 e 2010. Uma problemática tratada foi o fato de os limites dos setores censitários divergirem entre os períodos analisados. Como forma de propor uma solução para essa questão e possibilitar uma análise temporal do recorte da área estudada, a metodologia compreendeu o uso de imagens de sensoriamento remoto para o ajuste dos limites dos setores censitários e elaboração de mapas, gráficos e tabelas de crescimento populacional, densidade demográfica e edificações. Esses produtos evidenciaram a dinâmica da área em relação ao seu crescimento populacional. Com isso, o artigo contribui para discussões sobre um planejamento urbano que vise à melhoria da qualidade de vida da população, buscando priorizar ações que atendam demanda instalada e o incremento na demanda por infraestrutura e serviços urbanos. A 
metodologia aqui proposta mostra também que é viável o estudo combinado utilizando setores censitários e imagens de SR.

Palavras-chave: expansão urbana, setores censitários, sensoriamento remoto.

ABSTRACT: Urban sprawl in large Brazilian cities has intensified in recent decades, causing increased demand for urban infrastructure, urban services, and new areas for construction. The central goal of this article is to analyze the characteristics of urban expansion in the Canabrava community and its surroundings, in Salvador, Bahia, Brazil, using census data from 1991 and 2010 produced by the Brazilian Institute of Geography and Statistics (IBGE). One problem addressed was that the limits of the census tracts differed between the analyzed periods. To resolve this issue and enable a temporal analysis of the area studied, the methodology included the use of remote sensing images to adjust the boundaries of census tracts and to prepare charts, graphs, and tables of population growth and population and building density. These products showed the the dynamic of the area in relation to its population growth. Thus, the article contributes to a discussion of urban planning that aims to improve the population's quality of life, seeking to prioritize actions that meet new demands for infrastructure and urban services. In addition, the methodology proposed here demonstrates the feasibility of a study combining census tracts and remote sensing to accomplish these goals.

Keywords: urban sprawl, census tracts, remote sensing.

RESUMEN: La expansión urbana está ocurriendo con mayor intensidad en las últimas décadas en las grandes ciudades brasileñas, ocasionando una mayor demanda de infraestructura urbana, servicios y nuevas áreas para la construcción. El tema central de este artículo es analizar las características de la expansión urbana en la comunidad Canabrava y su entorno, en Salvador, Bahía, Brasil, utilizando los datos del censo del IBGE de 1991 y 2010. Uno de los problemas en la pesquisa fue que los límites de las secciones censales difieren entre los períodos analizados. Con el fin de proponer una solución a este problema y permitir un análisis temporal de la área de estudio, la metodología incluyó el uso de imágenes de sensores remotos para ajustar los límites de secciones censales y la preparación de mapas, gráficos y tablas de crecimiento poblacional, densidad de población y edificios. Estos productos mostraron la dinámica de la área de estudio relativa al crecimiento de su población. Así, el artículo contribuye a los debates sobre la planificación urbana 
dirigida a mejorar la calidad de vida de los habitantes, tratando de priorizar las acciones que satisfagan la actual demanda y el aumento de la demanda de infraestructura y servicios urbanos. La metodología propuesta también muestra que el estudio combinado utilizando secciones censales y las imágenes de teledetección es viable.

Palabras clave: expansión urbana, secciones de datos censales, teledetección.

\section{INTRODUÇÃO}

A expansão da área urbana, em especial dos condomínios residenciais, vem ocorrendo de forma intensa nas últimas décadas nas grandes cidades brasileiras, ocasionando aumento da demanda por infraestrutura urbana, serviços urbanos e por novas áreas para construções. Concomitante a esse processo, vem ocorrendo a expansão e adensamento de ocupações informais na cidade provocando um elevado incremento na demanda por infraestrutura e serviços urbanos. Essa situação vem provocando a redução de áreas com vegetação e gerando desigualdades sociais cada vez mais crescentes no espaço intraurbano, pois comunidades mais antigas instaladas de forma precária, em geral, não são beneficiadas pela melhoria nas condições de infraestrutura urbana proporcionada pela expansão do mercado imobiliário.

A área de estudo está localizada na porção central do território da cidade de Salvador, estado da Bahia, Brasil, na região conhecida como o "miolo” da cidade, conforme observado na Figura 1. Essa área está situada nas imediações da Av. Luís Viana Filho (conhecida como Av. Paralela), limitando-se ao sul com essa avenida que é atualmente o principal eixo viário do município, sendo considerada como a mais recente zona de expansão imobiliária da região metropolitana. Em virtude desse fator de proximidade, os terrenos circundantes se tornaram atraentes ao mercado imobiliário exercendo forte pressão para incorporação dessas áreas. Ao norte, a área de estudo limita-se pela Av. Aliomar Baleeiro - antiga Estrada Velha do Aeroporto, que funcionava como ligação ao aeroporto antes da construção da Av. Paralela -, a leste limita-se pelo vale do rio Mocambo (afluente do rio Trobogy) e a oeste abrange as áreas de influência direta das ruas Artêmio Castro Valente e Proc. Nelson Castro, principais vias que cortam a área. 


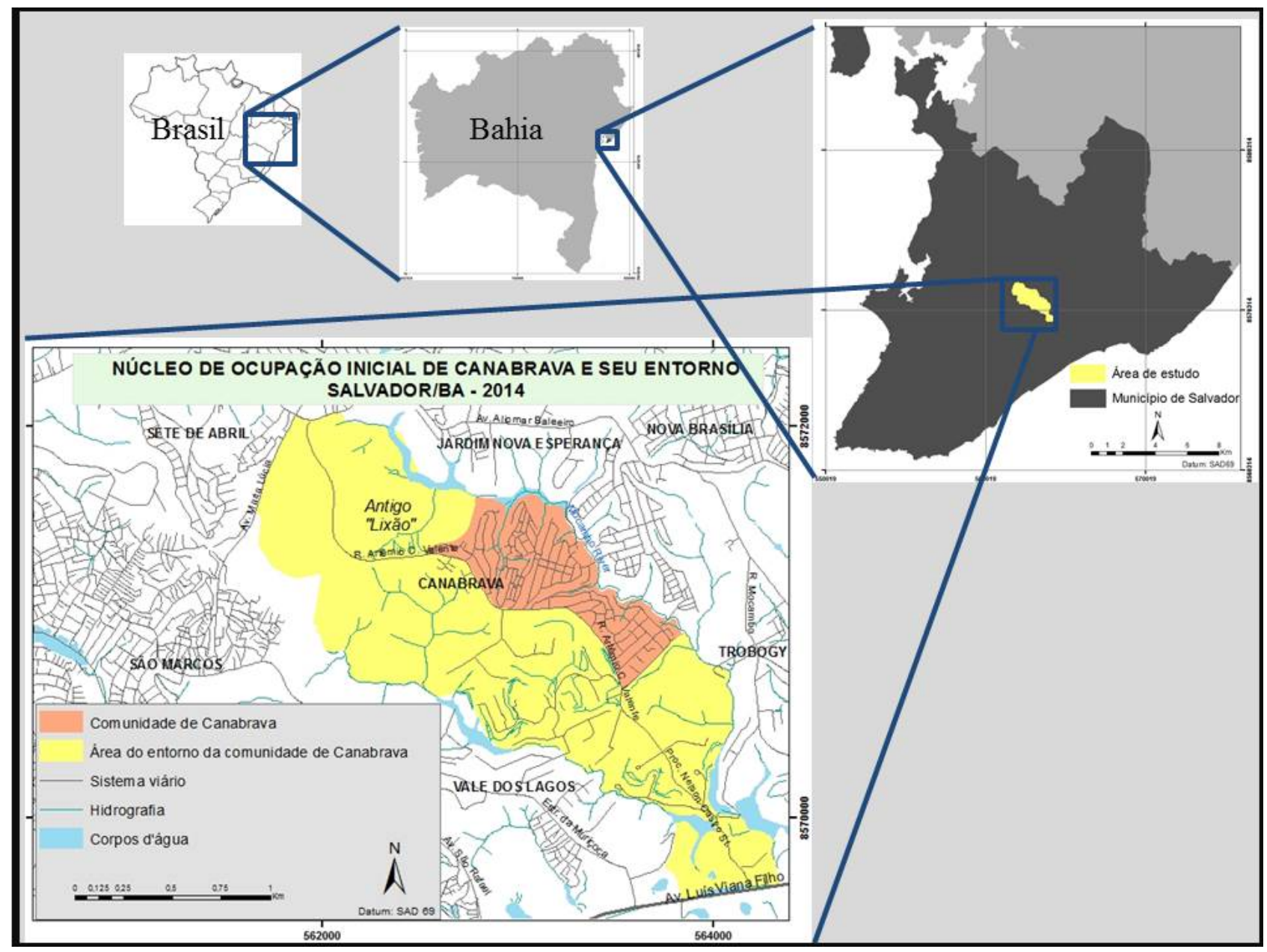

Fig. 1 Mapa de localização da área de estudo

A área de estudo teve como núcleo de ocupação inicial a comunidade de Canabrava que se originou, na década de 1970, a partir do remanejamento de populações de outras áreas da cidade em virtude de construção de novas avenidas e em decorrência das chuvas - e também por um núcleo de ocupação espontânea que atraía pessoas para a catação espontânea de lixo, pois nessa época aí era depositado todo o lixo da cidade sem qualquer tratamento. O “lixão” foi desativado em 1998, transformando-se em aterro sanitário controlado (ver figura 2), fazendo com que várias pessoas que viviam dessa atividade ficassem sem essa ocupação, agravando a questão social na área (PANGEA, 2010). 


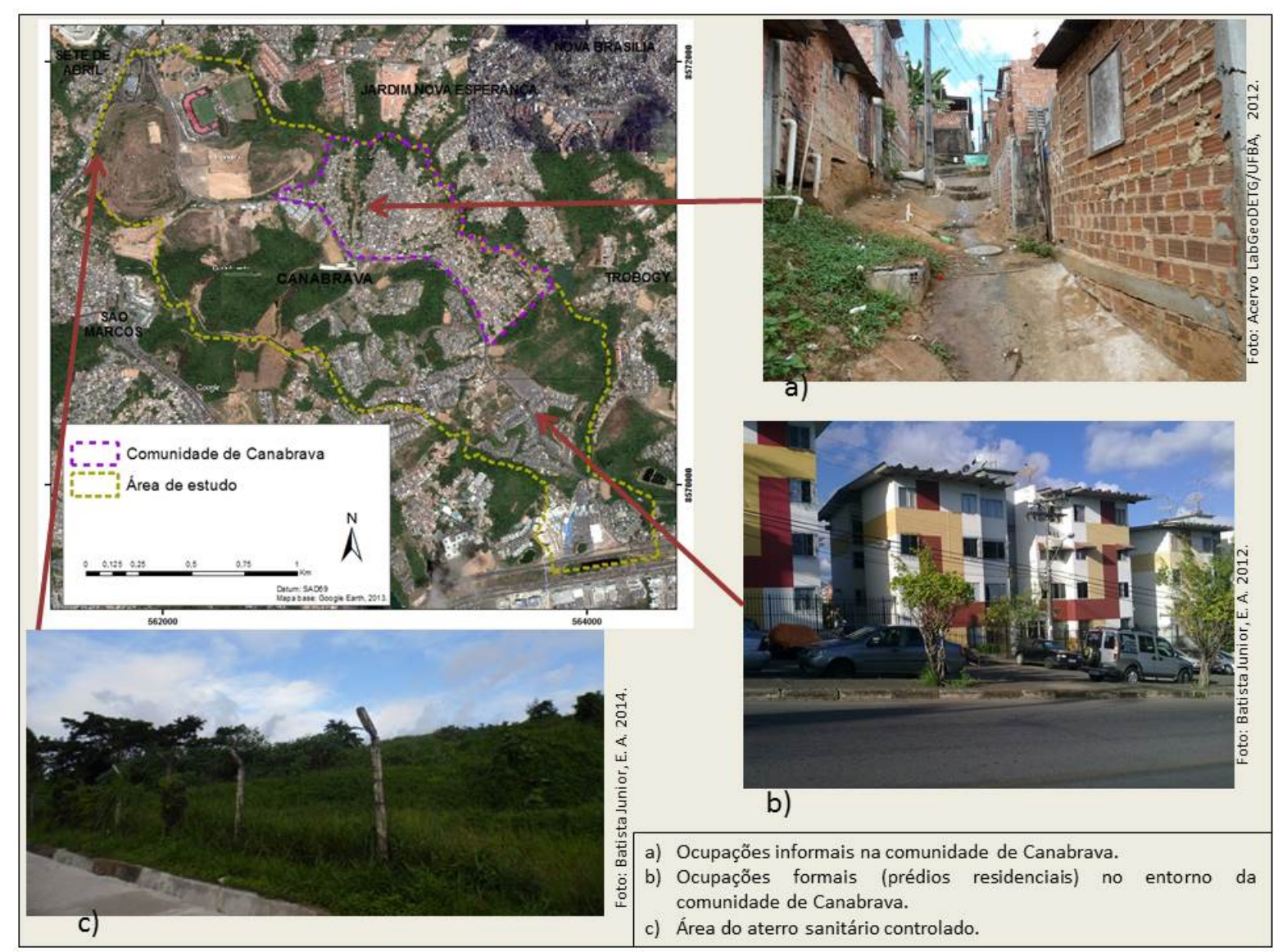

Fig. 2 Diferentes padrões de ocupação na área de estudo

As principais fontes de dados para o estudo dessa evolução demográfica são os Censos do IBGE, que têm como menos unidade espacial de agregação e disponibilização de informações os setores censitários. No entanto, os setores censitários do IBGE muitas vezes não mantêm a mesma configuração ao longo dos anos, fato que foi verificado na área de estudo. Isso dificulta uma análise comparativa na escala temporal. Da mesma forma, os limites não coincidem com o da área de estudo delimitada. Para contornar esse problema, a utilização de imagens de Sensoriamento Remoto (SR) pode se mostrar como uma eficiente solução. Dessa forma, este artigo utiliza, de forma combinada, os dados censitários e as imagens de SR para viabilizar o estudo na escala temporal.

A partir de uma revisão bibliográfica sobre a temática da expansão urbana mais amplo e com o objetivo de sua melhor compreensão, podem-se considerar três macro-fatores relacionados: expansão em área da cidade propriamente dita (expansão horizontal), adensamento da ocupação e oferta e qualidade da infraestrutura urbana como um todo. A expansão horizontal envolve três aspectos: crescimento da cidade formal, da informal e as características do uso e ocupação do solo 
no tempo. O crescimento da cidade formal é a dita cidade legal, com a ocupação e construção sobre terrenos cuja propriedade é legalizada. Nesse contexto, tem-se de um lado o indivíduo que financia a construção de sua casa própria e, de outro lado, o mercado imobiliário com empreendimentos residenciais e comerciais. Nesses casos, é importante que haja à priori ou que seja montada a infraestrutura urbana básica que possibilite haver residências e o desenvolvimento de atividades produtivas naquele local, tais como sistema de esgotamento sanitário e rede de energia elétrica. Normalmente esse sistema é provido pelo poder público antes da construção de empreendimentos ou casas. Já o crescimento da cidade informal se dá à margem das normas urbanísticas.

Em geral, quanto mais uma cidade se expande, mais densa ela se torna, com um número cada vez maior de habitações construídas. Assim sendo, esse aspecto envolve três processos: verticalização, aumento da área construída e crescimento populacional. O aumento da densidade populacional está diretamente relacionado ao crescimento da população e à verticalização. O crescimento populacional provoca um incremento de número de habitantes sobre o território municipal que, em regra, permanece o mesmo, provocando o adensamento da população com o aumento da área construída. É comum nos grandes centros urbanos esse processo culminar na verticalização das cidades, com a construção cada vez mais numerosa de prédios como forma de melhor aproveitamento do solo urbano e em resposta à escassez cada vez mais crescente de áreas disponíveis para construção. São vários os aspectos que determinam a forma e ritmo da verticalização, tais como o valor do solo, os agentes financeiros envolvidos, a atuação das empresas do mercado imobiliário, as diretrizes do estatuto da cidade e os impactos sociais, econômicos e ambientais decorrentes dos empreendimentos.

A infraestrutura urbana é um dos componentes importantes da expansão urbana. Isso ocorre em função de a infraestrutura urbana envolver os serviços e equipamentos urbanos essenciais ao atendimento das demandas do viver de determinada população, influindo diretamente na sua qualidade de vida. A infraestrutura possibilita o uso do espaço urbano, como afirma Mascaró (2005), sendo um elemento de associação entre a forma, a função e a estrutura nesse mesmo espaço. A infraestrutura urbana, de uma maneira geral, abrange os seguintes elementos: vias de circulação de pessoas e veículos, sistema de saneamento básico (abastecimento de água, esgotamento sanitário, drenagem e limpeza urbana), rede de energia elétrica, sistemas de comunicação e infraestrutura de espaços públicos para lazer, esporte e cultura. Existem serviços diretamente ligados à infraestrutura urbana, como o sistema de transporte em suas mais diversas modalidades, a educação, a saúde e a segurança pública. A infraestrutura urbana está diretamente relacionada a políticas públicas urbanas e a sua expansão, a expansão urbana é decorrência da articulação do mercado imobiliário com as 
políticas públicas que garantem a infraestrutura necessária a sua expansão, conforme explica Souza (2005). Assim sendo, os estudos que envolvem expansão urbana devem considerar a atuação das políticas públicas no meio urbano ao longo do tempo, evidenciando a forma como a população de determinada cidade é tratada quanto às suas demandas diárias por equipamentos e serviços urbanos. Nesse sentido, tem forte influência o capital imobiliário que atua no sentido de influenciar, em menor ou maior grau, as políticas públicas urbanas.

À margem das áreas de investimento do capital imobiliário, o crescimento da cidade informal se dá pela ocupação de terrenos ociosos pela população mais carente com a construção por conta própria de casas sem qualquer suporte técnico. A informalidade na ocupação urbana, de acordo com Gordilho-Souza (2008), refere-se à conformação de áreas fora dos padrões formais previstos para parcelamentos habitacionais, à revelia dos códigos e normas urbanísticas estabelecidas. Essas são as chamadas ocupações informais, podendo ser dos mais diversos tipos, tais como palafitas, casas de alvenaria ou de madeira. Essas ocupações, denominadas também de “invasões”, normalmente ocupam áreas com infraestrutura urbana precária e muitas vezes com inexistência da mesma. Maricato (2011) utiliza ainda o termo moradia precária, mais preciso que periferia urbana segundo a autora, pois se refere à generalização da ilegalidade e da precariedade para prover a moradia que não ocupa apenas a periferia urbana.

No atual molde como está se dando a expansão urbana no Brasil, as invasões normalmente ocorrem ao redor ou na periferia de bairros dotados de boa infraestrutura urbana, aproveitando-se da proximidade da dita “cidade formal” como solução aos problemas de mobilidade. A situação é mais crítica quando essas invasões ocupam a periferia urbana, localizando-se distante dos centros das atividades econômicas da cidade, fazendo com que haja uma demanda de transporte público para seus moradores que muitas vezes não é atendida ou, se o é, encontra-se de forma insatisfatória. Nos dois casos, a qualidade de vida da população dessa cidade informal é afetada seriamente necessitando de políticas públicas que solucionem ou minimizem seus problemas diários de moradia urbana.

Este artigo se propôs a utilizar imagens de sensoriamento remoto, que é um conjunto de processos e técnicas usados para medir propriedades eletromagnéticas de uma superfície ou de um objeto, sem que haja contato entre o objeto e o equipamento sensor (CÂMARA, 1996). A maioria dos sensores apresentam certas propriedades em comum, tais como: resolução espectral, resolução radiométrica, resolução espacial, resolução temporal (NOVO, 2008). A resolução espacial é a propriedade que define a capacidade do sensor detectar o objeto mínimo para se mapear. 
As imagens de sensoriamento remoto podem ser fotografias aéreas (sensor instalado no avião) e imagens orbitais (sensor instalado no satélite). As fotografias aéreas podem ser verticais e oblíquas. As fotografias aéreas verticais apresentam o eixo ótico da câmera para o mais vertical possível (ROSA, 2007) e são corrigidas geometricamente (x e y) tornando-se ortofotografias (JENSEN, 2009). As imagens verticais tomadas por sensores a bordo de satélites orbitais podem chegar a resoluções espaciais muito altas, a exemplo das imagens de grandes centros urbanos, como salvador, que são publicadas no Google Earth, permitindo a identificação de alvos urbanos como edificações, ruas e até calçadas.

O sensoriamento remoto vem sendo cada vez mais utilizado nos estudos de monitoramento do crescimento urbano. Almeida et al. (2006), por exemplo, apresentam um histórico da aplicação do processamento digital de imagens de satélites em estudos urbanos no Brasil desde a década de 1970. Essa pesquisa aponta que, com avanços na resolução espacial da ordem de $0,67 \mathrm{~m}$ a $1 \mathrm{~m}$ na banda pancromática e 4m nas multiespectrais - alta e altíssima resolução espacial - a nova geração de sensores orbitais representa uma revolução tanto em termos de métodos de processamento de imagens, bem como no nível de detalhamento do cenário urbano, possibilitando formas promissoras de exploração do universo intraurbano e ampliando os horizontes de aplicações do SR com fins ao planejamento físico-territorial e ambiental. No atual cenário, as imagens de alta resolução são imprescindíveis para se trabalhar com o monitoramento das mudanças do uso do solo urbano, conforme afirmam Leite et al. (2014), haja vista que a série histórica de produtos orbitais pode revelar a dinâmica da cidade em um recorte temporal.

Lombardo (1996) já afirmava que o SIG possibilitava a plena utilização de imagens de SR focalizando a realidade urbana, tornando possível o monitoramento temporal compatível com a velocidade das mudanças que ocorrem nas grandes cidades. Assim sendo, verifica-se que são várias as possibilidades de aplicação do SR nos estudos dos diversos fenômenos que ocorrem no meio urbano, a exemplo da pesquisa feita por Martins e Leite (2015) que analisou o crescimento das favelas e por Brito (2010) que investigou padrões urbanos associados à ocorrência da leptospirose ambas pesquisas com uso de imagens de alta resolução espacial e SIG. Ou ainda estudos como o realizado por Volpe e Lombardo (2011) que analisou a dinâmica temporal do uso da terra na margem de um eixo rodoviário na cidade de São Paulo, tendo utilizado fotografias aéreas e imagem de alta resolução (IKONOS).

\section{OBJETIVOS E METODOLOGIA}


Este artigo se propõe a estudar as características da expansão urbana na comunidade de Canabrava e em seu entorno a partir do uso de dados dos censos demográficos do IBGE de 1991 e 2010 e imagens de sensoriamento remoto de 1992 e 2013. Assim sendo, o objetivo principal é propor um método híbrido de utilização de imagens de SR e dados censitários, de forma a extrair informações quantitativas e qualitativas a respeito da evolução urbana da área entre os anos de 1991 e 2013. Para tal, pretende-se analisar o crescimento populacional através do estudo de taxas de crescimento e adensamento populacional.

Este tipo de estudo se justifica por contribuir para discussões que busquem um planejamento urbano eficaz no sentido de propor alternativas que possibilitem a melhoria da qualidade de vida da população como um todo. A partir do conhecimento das características demográficas de determinada porção da cidade, há um melhor suporte na priorização mais ajustada de ações que atendam demanda instalada e o incremento na demanda por infraestrutura e serviços urbanos. Da mesma forma, ao propor uma metodologia de utilização conjunta de dados censitários com imagens de sensoriamento remoto, torna-se uma referência metodológica para trabalhos que pretendam fazer essa mesma utilização conjunta, sendo uma possível solução para contornar determinadas incompatibilidades, tal como a diferença de limites entre os setores censitários ao longo dos anos.

Este estudo partiu de levantamento bibliográfico e documental sobre a área de estudo e suas caraterísticas demográficas. A consulta do material bibliográfico foi efetuada na rede de bibliotecas da Escola Politécnica, da Faculdade de Arquitetura e Urbanismo e do Instituto de Geociências da Universidade Federal da Bahia (UFBA), em sítios de universidades públicas na internet, no portal de periódicos da CAPES e do Scielo na internet, em sítios na internet de instituições públicas e privadas possuem informações sobre a área, tais como CONDER, IBGE e PANGEA. Foram utilizados dados da cartografia base da cidade de Salvador disponibilizadas pela CONDER, referentes a versão de 1992, na escala 1:2.000, e de 2012, com edições e atualizações do sistema viário realizadas por equipe de pesquisadores do LabGeo/DETG/UFBA em 2012. Os dados utilizados dessa fonte foram hidrografia - composta pelas informações de rios, corpos d’água e sistema viário.

Os limites geográficos dos setores censitários de 1991 e 2010 foram obtidos no banco de dados do IBGE, em seu sítio na internet, em formato "shapefile”. Os dados estatísticos fornecido pelo IBGE referente aos censos em questão, também foram obtidos em formato de tabela, sítio do IBGE. 
As imagens de sensoriamento remoto foram obtidas de duas fontes, a saber: a imagem de 1992 trata-se de um mosaico de fotografias aéreas pancromáticas na escala de 1:10.000 disponibilizadas pela CONDER; a imagem de 2013 foi obtida a partir do georreferenciamento de um mosaico de imagens de alta resolução publicadas no Google Earth.

A delimitação da área de estudo foi feita com base na área de contribuição viária relacionada à área do estudo. Os limites da área foram ajustados em cima dos limites de bairro considerado por Santos et al. (2010), na publicação “O Caminho das Águas em Salvador”. Foram consideradas as áreas de influência das duas principais vias que cortam o bairro, as ruas Artêmio Castro Valente e Proc. Nelson Castro, que servem de ligação entre a Av. Aliomar Baleeiro (conhecida como Estrada Velha do Aeroporto, por ser o antigo eixo de ligação ao aeroporto de Salvador) e a Av. Luís Viana Filho (Av. Paralela). A porção a leste da comunidade de Canabrava, correspondente à área dos bairros Jardim Nova Esperança, Nova Brasília e Trobogy, por não possuírem uma interação socioeconômica e de fluxos com a área - devido à configuração do relevo, sendo o divisor dessas áreas o vale do rio Mocambo, e também ao fato de não existir vias de circulação ligando diretamente Canabrava a essas áreas, não tendo, portanto, contiguidade de fluxos - não foi considerada dentro da área estudada.

A partir do material levantado, foram executados os procedimentos metodológicos, cujo fluxograma geral pode ser visto na Figura 3, a seguir: 


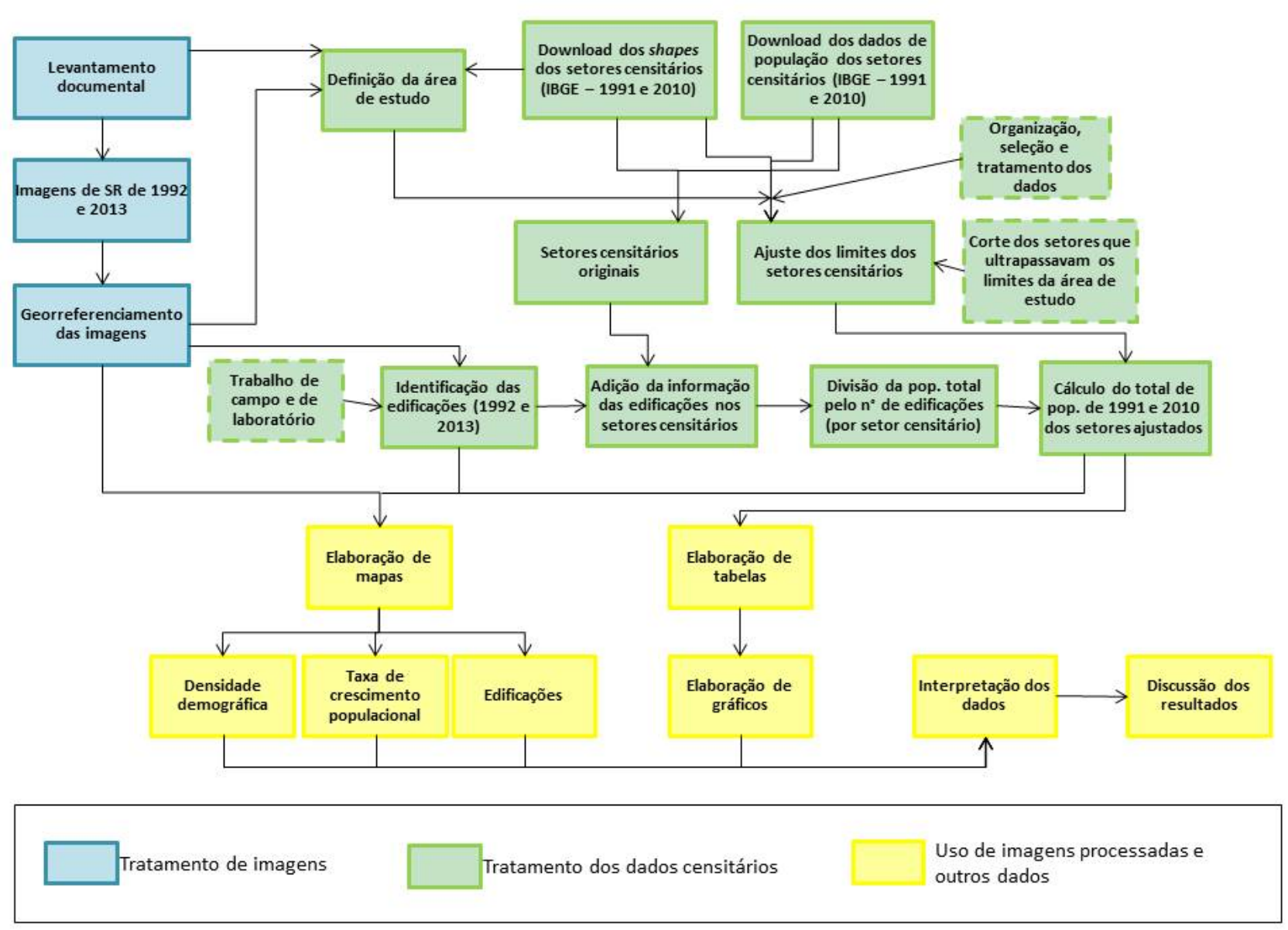

Fig. 3 Fluxograma geral dos procedimentos metodológicos

As etapas desenvolvidas na metodologia foram as seguintes:

1 - georreferenciamento das imagens com uso do software Quantum GIS 1.8.0;

2 - tratamento dos dados censitários com recorte dos setores censitários que abrangiam a área de estudo, conforme ilustrado na Figura 4;

3 - processamento dos dados para elaboração de tabelas e gráficos das taxas de crescimento populacional, de edificações e de densidade demográfica;

4 - elaboração dos mapas de densidade populacional, de taxa de crescimento populacional e de edificações;

5 - interpretação dos dados e discussão dos resultados. 


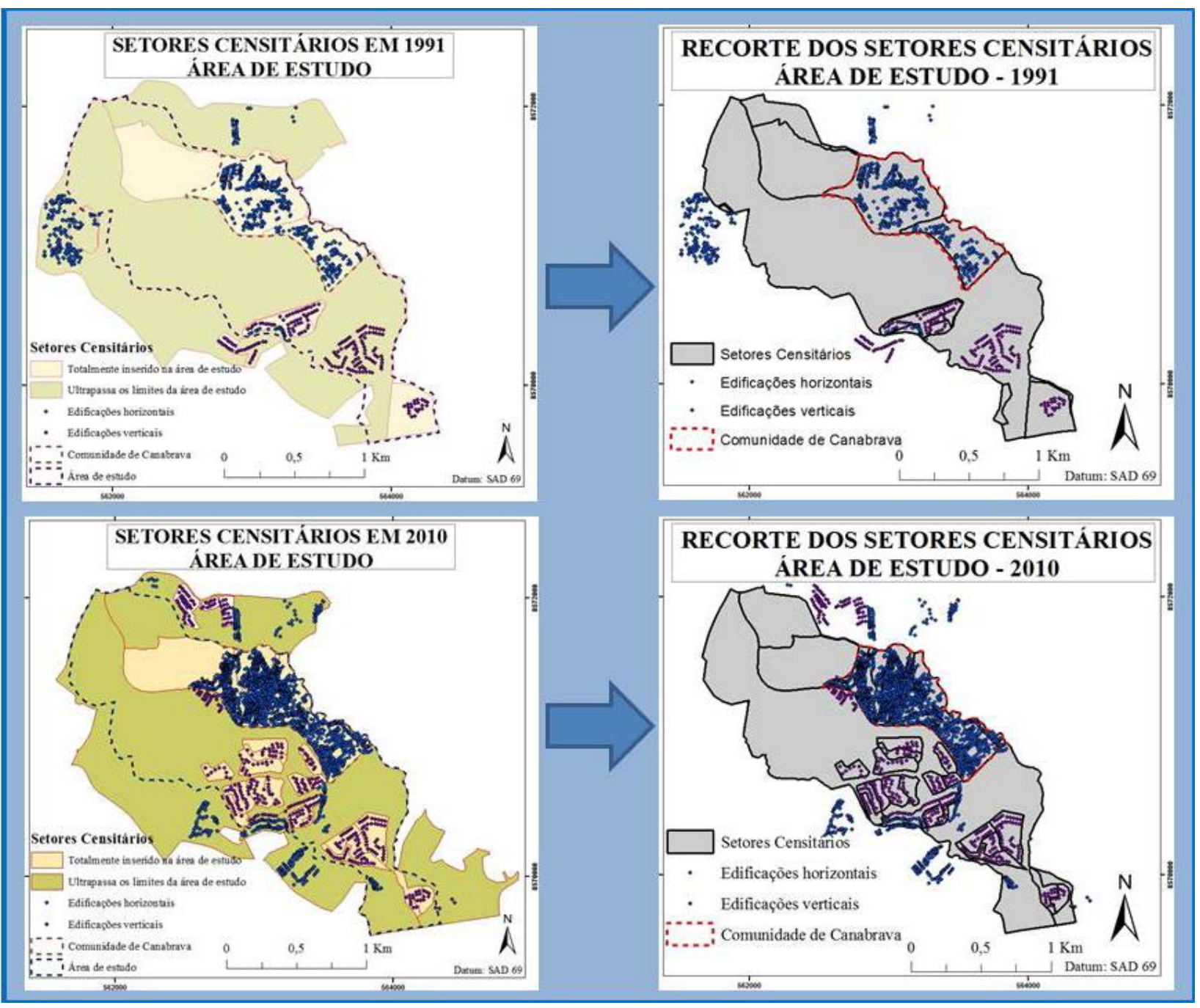

Fig. 4 Esquema de tratamento dos setores censitários

Os setores censitários de 1991 e 2010 não coincidem nem quanto ao número nem quanto aos limites. Em função disso, os ajustes dos setores foram feitos com utilização de imagens verticais mais próximas dos anos dos dados censitários disponíveis (1991 e 2010), assim sendo foram usadas as imagens de 1992 e 2013. Sendo assim, a etapa 2 descrita no parágrafo anterior e ilustrada na Figura 4 foi a mais complexa e envolveu as seguintes fases:

a) identificação e seleção dos setores censitários que abrangiam a área de estudo;

b) marcação com pontos de todas as edificações horizontais e verticais presentes nos setores selecionados a partir das imagens de 1992 e 2013, sendo que para as edificações verticais foi verificado em campo, em 2013, e por meio do "Street View" do Google Earth o número de apartamentos e pavimentos para saber o número total de domicílios por prédio. 
c) cálculo do quanto cada domicílio correspondia em população, dividindo-se o número total de população do setor censitário pela quantidade de domicílios nele existentes;

d) corte dos setores que ultrapassavam os limites da área de estudo, estimando o novo valor de população do setor com base no número de domicílios presentes - tendo sido calculado esse número por edificações verticais existentes considerando o número de pavimentos e de apartamentos por andar - na parte recortada do setor que ficou dentro da área de estudo; o número de domicílios foi multiplicado por seu valor médio de habitantes para obter o total da população do setor;

e) recálculo da área (em hectares) dos setores recortados;

f) cálculo da densidade demográfica dos novos setores recortados, a partir da população estimada calculada e da nova área;

g) sobreposição dos domicílios com seu valor médio de número de pessoas de 1991 à base de setores de 2010 para saber, para cada setor de 2010, qual o número de população correspondente em 1991.

h) cálculo da taxa de crescimento com base nos setores de 2010, com uso dos dados de 1991 sobrepostos a cada setor.

\section{RESULTADOS E DISCUSSÃO}

O tratamento dos dados obtidos a partir do cruzamento das imagens de sensoriamento remoto com os setores censitários possibilitou o conhecimento do ritmo de crescimento populacional e de seu adensamento na área de estudo. Ao se analisar os dados de população absoluta, conforme mostrados na Tabela 1, pode ser verificado que enquanto a comunidade teve um aumento de 80,68\% de 1991 para 2010, seu entorno apresentou um aumento muito superior no mesmo período, sendo de 181,73\%. Esses percentuais, assim como a taxa de crescimento populacional da área como um todo (133,95\%) estão muito acima da taxa apresentada pelo município de Salvador para o mesmo período, que foi de 29,04\%, atingindo a marca de 2.675.656 habitantes em 2010, de acordo com o IBGE. O ritmo de evolução da população absoluta na comunidade e seu entorno pode ser mais bem visualizado na Figura 5. 
Tabela 1 Dados populacionais de Canabrava e entorno de 1991 a 2010

\begin{tabular}{|c|c|c|c|c|c|c|c|}
\hline & \multicolumn{2}{|c|}{ População Absoluta } & \multirow{2}{*}{$\begin{array}{l}\text { Aumento 1991-2010 } \\
\quad\left(\mathrm{n}^{\circ} \text { absoluto }\right)\end{array}$} & \multirow{2}{*}{$\begin{array}{c}\text { Aumento 1991-2010 } \\
\text { (em \%) }\end{array}$} & \multirow{2}{*}{$\begin{array}{l}\text { ÁREA } \\
\text { (ha) }\end{array}$} & \multicolumn{2}{|c|}{$\begin{array}{c}\text { População Relativa } \\
\text { (habitantes/ha) }\end{array}$} \\
\hline & 1991 & 2010 & & & & 1991 & 2010 \\
\hline $\begin{array}{c}\text { Comunidade de } \\
\text { Canabrava }\end{array}$ & 4.266 & 7.708 & 3.442 & 80,68 & 45,58 & 93,60 & 169,12 \\
\hline $\begin{array}{c}\text { Entorno da Comunidade } \\
\text { de Canabrava }\end{array}$ & 4.756 & 13.399 & 8.643 & 181,73 & 226,53 & 21,00 & 59,15 \\
\hline Área de estudo & 9.022 & 21.107 & 12.085 & 133,95 & 272,10 & 33,16 & 77,57 \\
\hline
\end{tabular}

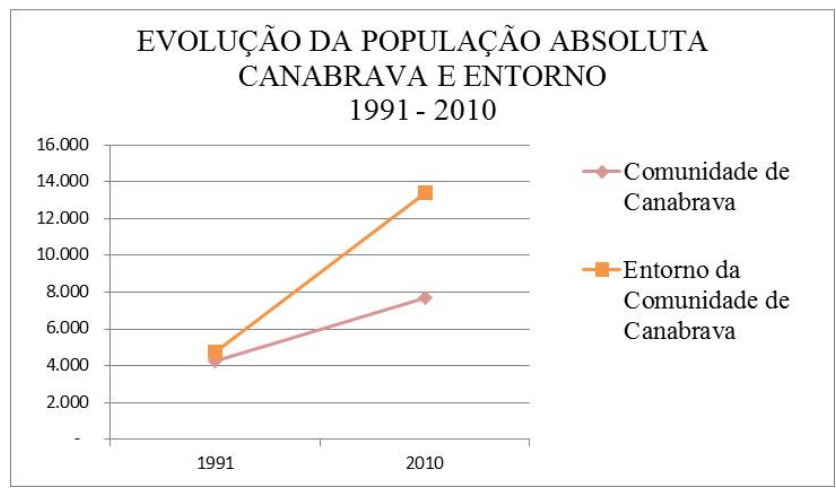

Fig. 5 Evolução da população absoluta em Canabrava e entorno de 1991 a 2010

O número de edificações aumentou consideravelmente na área de estudo, conforme pode ser visualizado na Tabela 2. Existe, entretanto, um padrão diferenciado entre a comunidade e seu entorno. Na primeira só existem edificações horizontais (casas) em virtude de suas características de ocupação. Já no entorno há predomínio de edificações verticais (prédios), em razão do avanço dos condomínios residenciais na área. Essas características se mantêm de 1991 para 2010, cabendo destacar que houve grande elevação do número de todas as edificações na área como um todo. A distribuição das edificações, nos anos de 1991 e 2010, pode ser melhor visualizada nas Figuras 6 e 7, respectivamente.

Tabela 2 Edificações na área de estudo 


\begin{tabular}{|c|c|c|c|c|c|c|c|c|}
\hline \multirow{2}{*}{ Área } & \multicolumn{2}{|c|}{1991} & \multicolumn{2}{|c|}{2010} & \multicolumn{2}{|c|}{$\begin{array}{c}\text { Aumento 1991-2010 } \\
\left(n^{\circ} \text { absoluto }\right)\end{array}$} & \multicolumn{2}{|c|}{$\begin{array}{c}\text { Aumento 1991-2010 } \\
\text { (em \%) }\end{array}$} \\
\hline & $\begin{array}{l}\text { Edificações } \\
\text { horizontais }\end{array}$ & $\begin{array}{c}\text { Edificações } \\
\text { verticais }\end{array}$ & $\begin{array}{l}\text { Edificações } \\
\text { horizontais }\end{array}$ & $\begin{array}{l}\text { Edificações } \\
\text { verticais }\end{array}$ & $\begin{array}{l}\text { Edificações } \\
\text { horizontais }\end{array}$ & $\begin{array}{c}\text { Edificações } \\
\text { verticais }\end{array}$ & $\begin{array}{l}\text { Edificações } \\
\text { horizontais }\end{array}$ & $\begin{array}{c}\text { Edificações } \\
\text { verticais }\end{array}$ \\
\hline Comunidade de Canabrava & 429 & 0 & 1700 & 0 & 1271 & 0 & 296,27 & 0 \\
\hline $\begin{array}{c}\text { Entorno da comunidade de } \\
\text { Canabrava }\end{array}$ & 20 & 153 & 108 & 317 & 88 & 164 & 440,00 & 107,19 \\
\hline Área de estudo & 449 & 153 & 1808 & 317 & 1359 & 164 & 302,67 & 107,19 \\
\hline
\end{tabular}

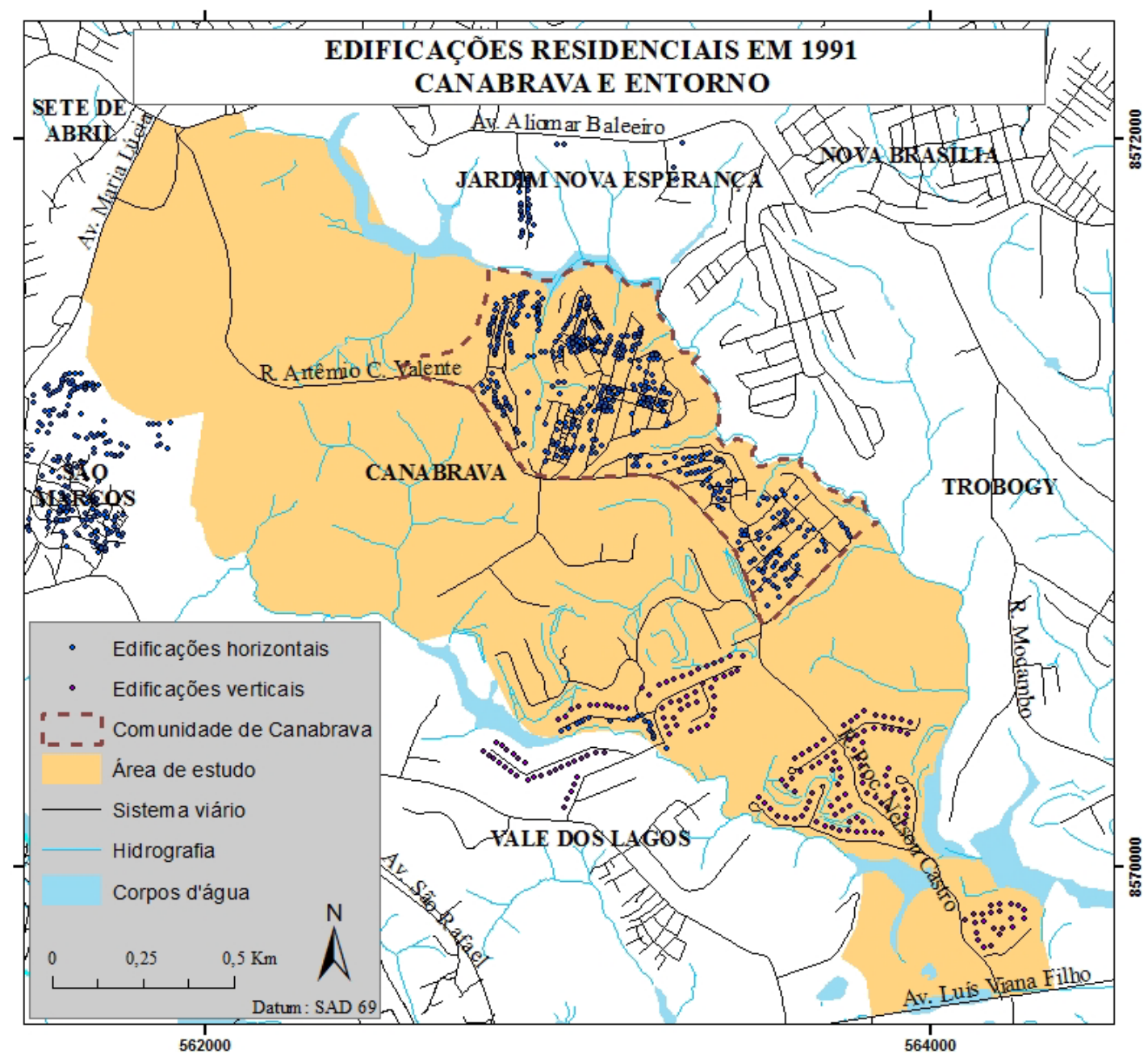

Fig. 6 Edificações residenciais na área de estudo em 1991 


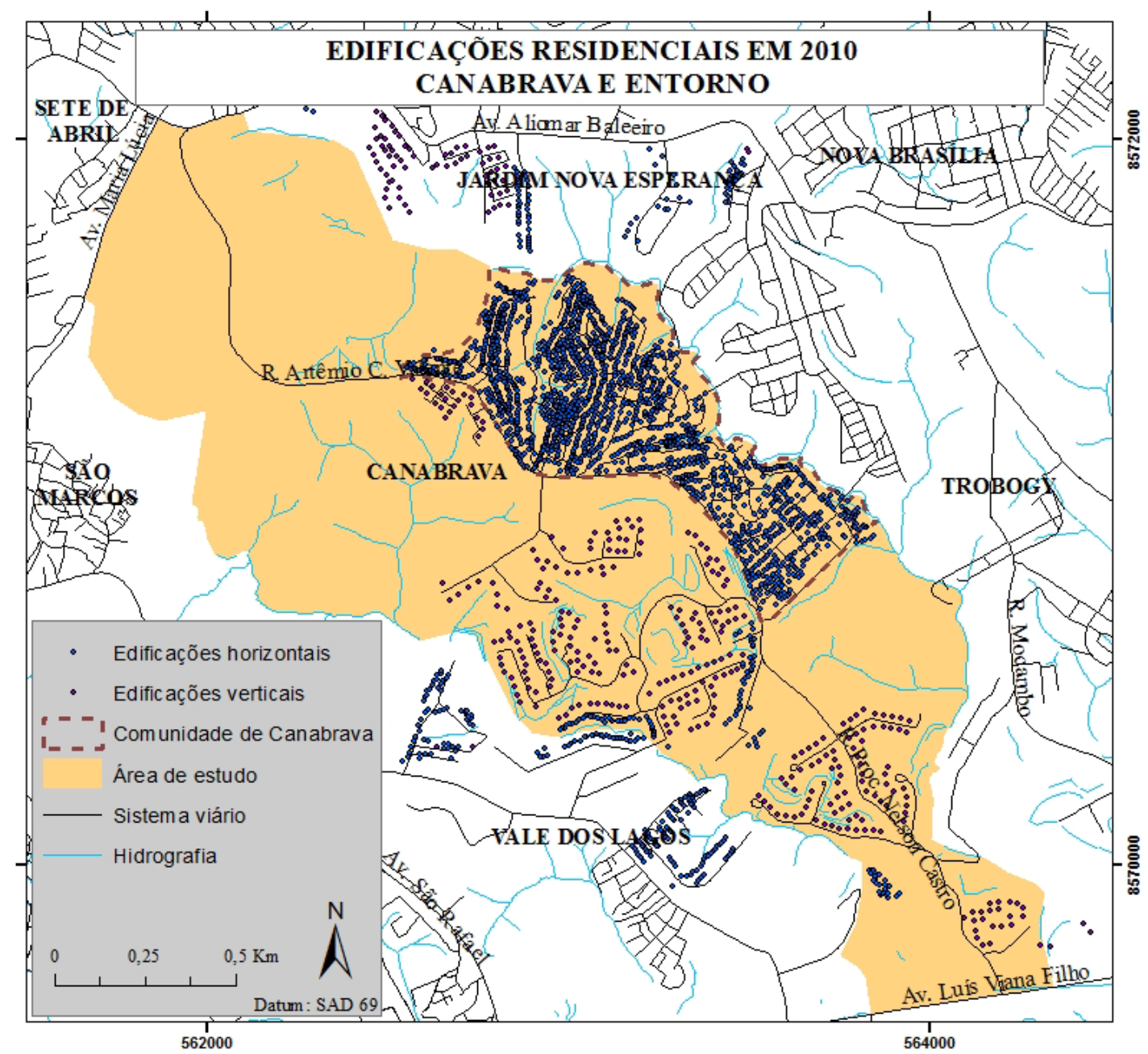

Fig. 7 Edificações residenciais na área de estudo em 2010

Os dados sobre edificações e de população demonstram o grande adensamento populacional que ocorreu. Tanto a comunidade como um todo, quanto seu entorno, tiveram elevação acentuada na densidade demográfica, conforme pode ser visualizado na Figura 8.

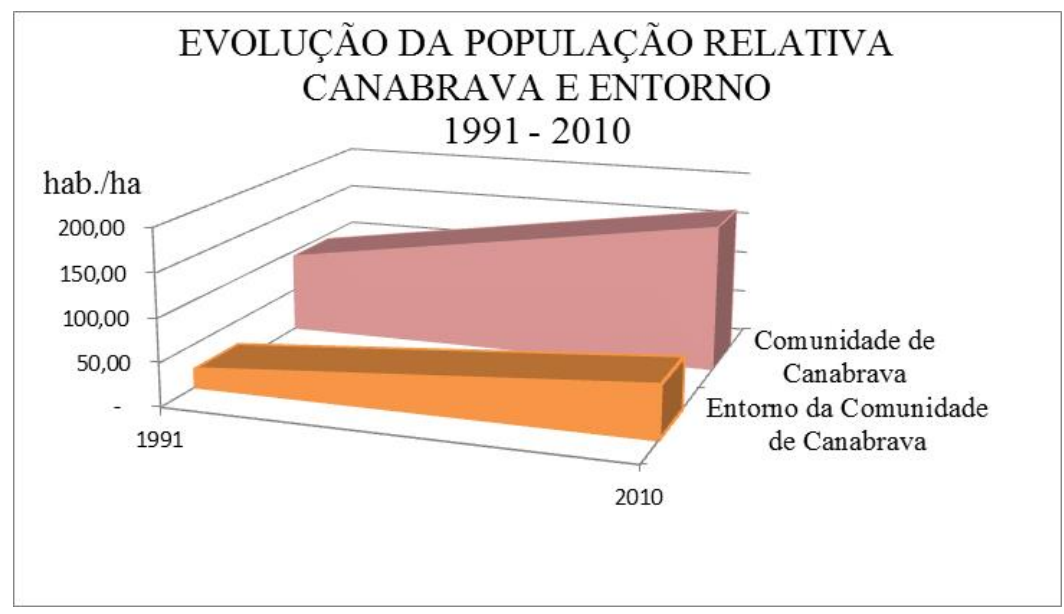

Fig. 8 Gráfico de evolução da população relativa de 1991 a 2010 na área de estudo 
A comparação entre os mapas de densidade demográfica dos anos de 1991 e 2010, apresentados na Figura 9, imagens a) e b) respectivamente, permite perceber o quanto a área adensou em localizações específicas no entorno. As áreas que mais se adensaram foram aquelas onde se situam condomínios residencias, conforme pode ser percebido a partir do cruzamento com o mapa de edificações, apresentado na Figura 7. Por ter relativamente uma grande área, o entorno ainda permanece com muitos "vazios urbanos”. O mesmo não ocorre com a comunidade, cuja área apresentou um grande adensamento populacional.

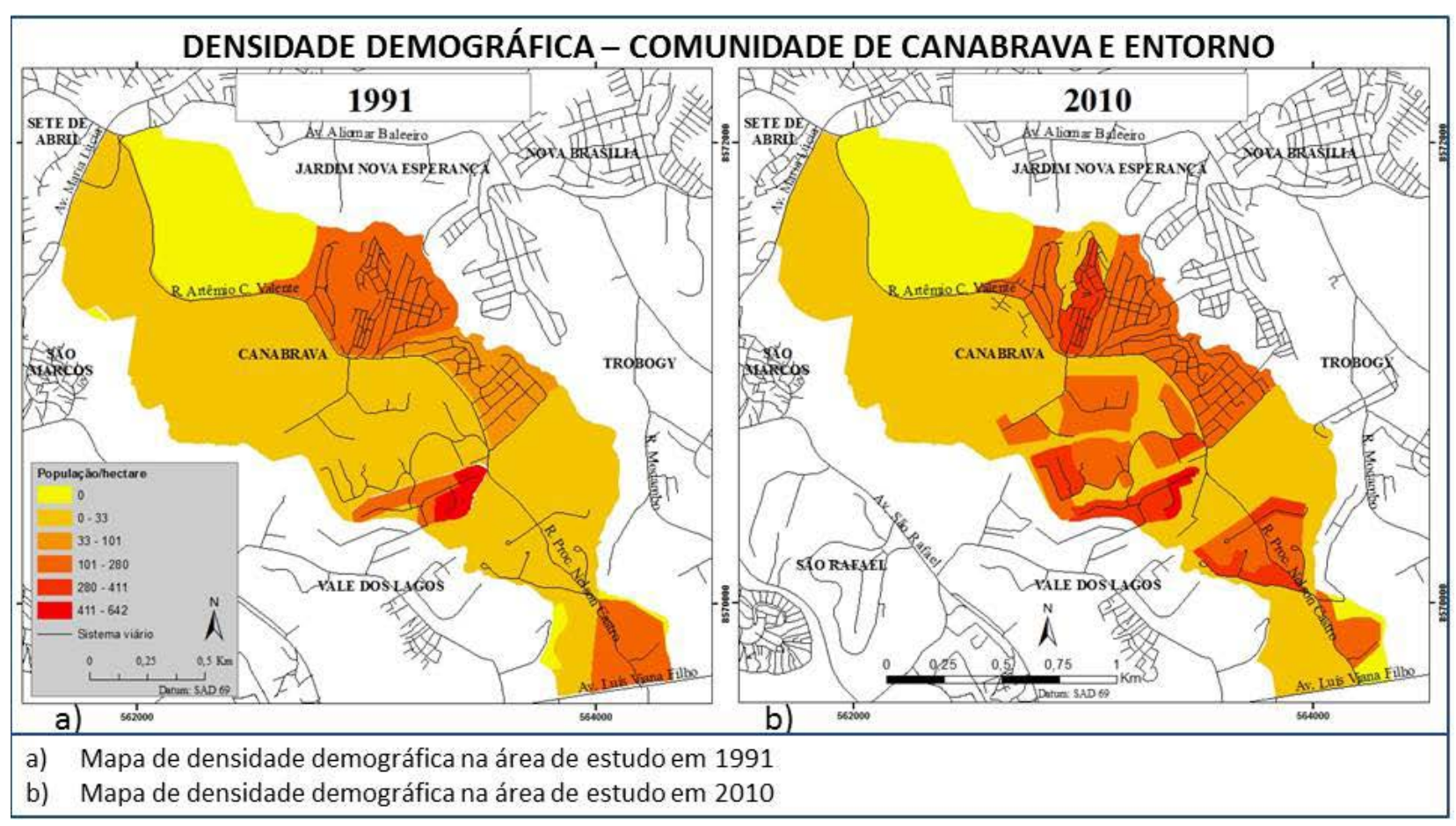

Fig. 9 Mapas de densidade populacional em 1991 e 2010 da área de estudo

O cruzamento das informações dos setores de 1991 e 2010 permite verificar as áreas que mais sofreram incremento populacional, conforme pode ser observado na Figura 10. A partir da análise do mapa, observa-se que houve um incremento de 0 a 100 habitantes por hectare na maior parte da área de estudo no período considerado. Em grande parte da comunidade houve incremento de 200 a 300 habitantes por hectare. Os maiores incrementos de habitantes (de 300 a 400 hab./ha) ocorreram em áreas de condomínios residenciais no entorno da comunidade. 


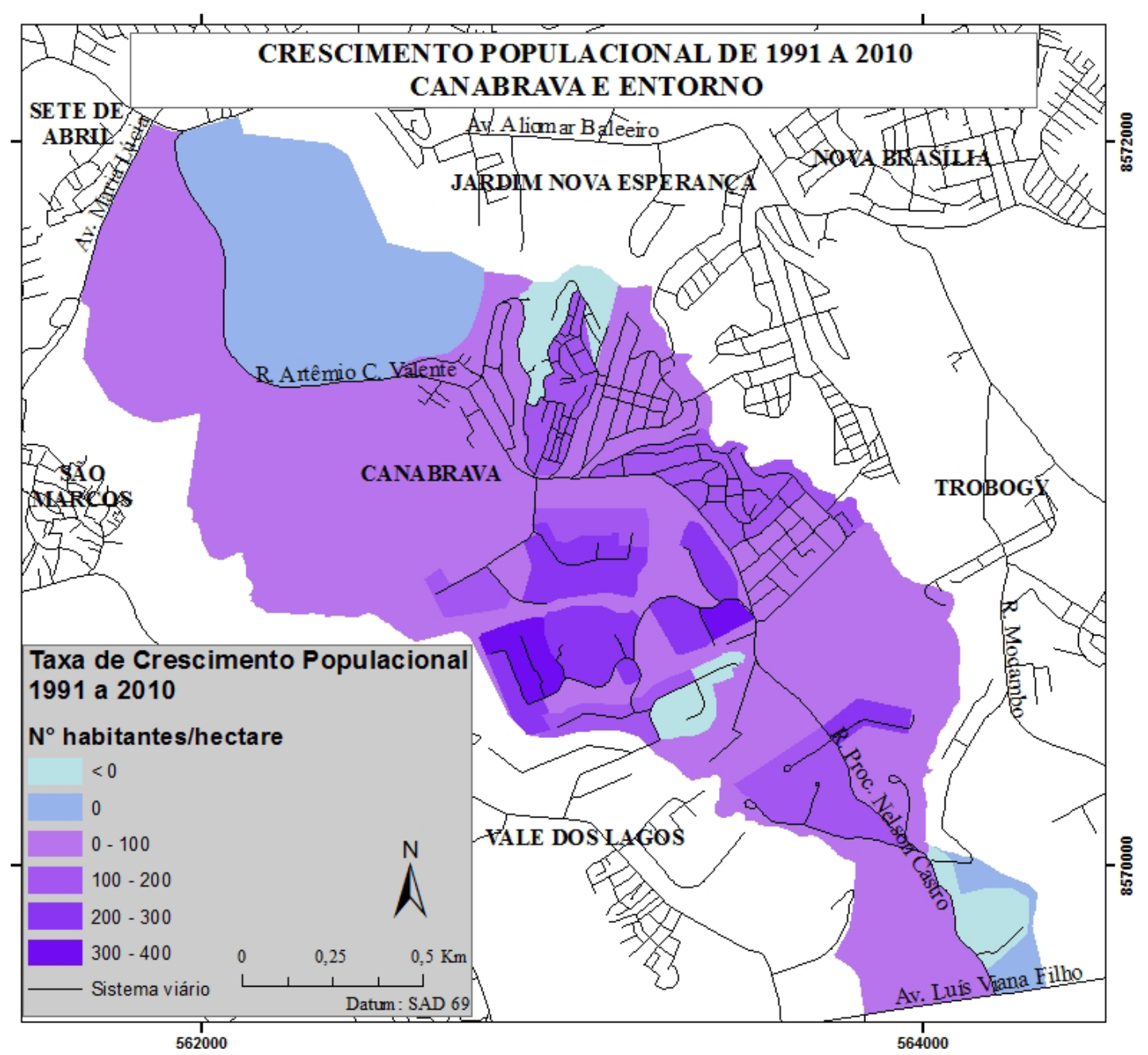

Fig. 10 Mapa de crescimento populacional de 1991 a 2010 na área de estudo

A análise dos mapas, gráficos e tabelas apresentados permite constatar que a área de estudo como um todo vem apresentando elevadas taxas de crescimento populacional, culminando no aumento da demanda por infraestrutura e serviços urbanos. Entretanto, a comunidade de Canabrava se diferencia do seu entorno quanto às características desse crescimento. Enquanto a primeira apresenta o crescimento de uma população em ocupações informais e, na maioria dos casos, em precárias condições de moradia, seu entorno vem apresentando a evolução da ocupação formal, quase que em sua totalidade representada pela expansão de condomínios residenciais de prédios. Isso vem demonstrando a forte atuação do capital imobiliário na área e, vale destacar, que esse entorno ainda possui grandes áreas de interesse para atuação do mercado imobiliário e da construção civil. 
Nesse contexto, se essa tendência de crescimento diferencial entre a comunidade e seu entorno se mantiver nos próximos anos, ocorrerá a intensificação da ocupação formal do entorno por condomínios residenciais e do adensamento por ocupações informais na comunidade. Essa tendência vem sendo reforçada pela influência da Av. Paralela, que torna atrativa a área do ponto de vista da expansão imobiliária, fato que poderá culminar na acentuação do “abismo” existente entre as condições de infraestrutura e serviços urbanos da comunidade e do seu entorno, apresentando este último melhoria em detrimento daquela.

A utilização de dados de setores censitários permitiu perceber que, ao se trabalhar com dados espacializados, deve-se ter cuidado com a representatividade dos mesmos. Isso se deve ao fato de que, em razão de muitos setores censitários possuírem grande extensão e em virtude de sua conformação, os dados podem levar a equívocos na interpretação como, por exemplo, uma área específica pode ter um forte adensamento populacional e, por estar inserida num setor censitário de grande extensão, pode ser interpretada erroneamente como não adensada. Isso demonstra a grande importância em se adequar os limites dos setores censitários, fazendo os devidos cálculos de ajuste em sua área e população absoluta, assim como de outros dados que se façam necessários ao estudo. A adequação desses limites se torna possível através do uso de imagens de sensoriamento remoto com dada resolução espacial que permita a identificação de edificações para, a partir daí, fazer o cálculo de médias que possibilitem uma melhor espacialização dos dados, o mais próximo do real. O ideal é utilizar imagens do mesmo ano do censo que o setor representa ou, se não for viável, o mais próximo possível, assim como foi feito neste estudo.

A metodologia adotada neste trabalho, por utilizar imagens de Sensoriamento Remoto e dados censitários de forma conjunta, mostrou-se eficaz e, portanto, viável para ser replicada em estudos semelhantes que busquem a análise da dinâmica populacional em áreas específicas.

A relevância de estudos como este se deve, dentre outros fatores, ao fato de viabilizar a representação espacial da dinâmica populacional no espaço intraurbano. Isso se configura como uma ferramenta eficaz na análise da cidade e dos processos que nela ocorrem, em suas mais variadas escalas, contribuindo para o debate científico, no intuito de entender o funcionamento do meio urbano e propor alternativas que busquem a melhoria da qualidade de vida nesse meio. Sendo assim, mais contribuições podem ser somadas com a realização de pesquisas que utilizem dados censitários e sensoriamento remoto numa escala de tempo maior, em lugares com características diversas dentre de uma mesma cidade, buscando entender sua dinâmica e propor soluções para os problemas encontrados. 
Este estudo torna evidente a necessidade de adoção de políticas públicas que considerem a dinâmica espaço-temporal e a configuração dos diferentes padrões de ocupação dos espaços intraurbanos. O planejamento urbano eficaz e os mecanismos de intervenção urbana devem considerar a análise do crescimento populacional, num dado intervalo de tempo, considerando as peculiaridades dos diferentes lugares da cidade, a fim de estimar o grau de demanda instalada e de incremento na demanda por infraestrutura e serviços urbanos impostos pelos novos condomínios, como é o caso de Canabrava, fazendo com que esse investimento se estenda a áreas circunvizinhas negligenciadas. Com isso, o poder público pode e deve buscar atender um incremento populacional proporcionando a melhoria da qualidade de vida no meio urbano instalado e em processo de instalação.

\section{REFERÊNCIAS}

ALMEIDA, C. M. de et al. O sensoriamento remoto como instrumental para o mapeamento da urbanização dispersa. In: Anais do 1 Seminário Internacional sobre Urbanização Dispersa e Mudanças no Tecido Urbano. São Paulo: FAUUSP, 2006. Disponível em: < http://mtcm17.sid.inpe.br/col/sid.inpe.br/mtc-m17@80/2007/10.08.15.16/doc/Artigo_Livro_FAUUSP.PDF>. Acesso em: 28 jun. 2015.

BRITO, P. L.. Sensoriamento remoto na identificação de elementos e tipologias urbanas relacionados à ocorrência da leptospirose no subúrbio ferroviário de Salvador, Bahia. 2010. Tese (Doutorado) - Escola Politécnica, Universidade de São Paulo, São Paulo, 2010.

CÂMARA, G. Geoprocessamento para Projetos Ambientais. São José dos Campos: INPE, 1996.

CONDER. Base Cartográfica SICAR/RMS: Município de Salvador anos 1976 e 1992 escalas 1:8.000 e 1:10.000 - Fotografias Aéreas Verticais. Salvador: CONDER/INFORMS, 1992. 
GORDILHO-SOUZA, A. G. Limites do habitar: segregação e exclusão na configuração urbana contemporânea de Salvador e perspectivas no final do século XX. 2. ed. Salvador: EDUFBA, 2008. 496p.

IBGE. Banco de dados do Censo Demográfico de 1991. Disponível em: <http://www.ibge.gov.br/home/estatistica/populacao/censodem/>. Acesso em: 09 jan. 2014.

IBGE. Banco de dados do Censo Demográfico de 2010. Disponível em: $<$ http://www.ibge.gov.br/home/estatistica/populacao/censo2010/caracteristicas_da_populacao/defau lt_caracteristicas_da_populacao.shtm>. Acesso em: 01 jan. 2014.

JENSEN, J. R. Sensoriamento Remoto do Ambiente: Uma perspectiva em recursos terrestres. São José dos Campos, SP: Parêntese, 2009.

LEITE, M. E. et al. Monitoramento da dinâmica no uso do solo urbano de Montes Claros/MG por imagens de alta resolução espacial. In: Caminhos de Geografia (UFU), v. 15, p. 172-180, 2014. Disponível em: <http://www.seer.ufu.br/index.php/caminhosdegeografia/article/viewFile/26366/15468>. Acesso em: 18 jun. 2015.

LOMBARDO, M. A. Aplicação das técnicas de sensoriamento remoto e sistemas de informações geográficas nos estudos urbanos. In: Revista do Departamento de Geografia (USP), São Paulo, v. 10, 1996. Disponível em: <http://www.revistas.usp.br/rdg/article/viewFile/53700/57663>. Acesso em: 25 jun. 2015.

MARICATO, E. O impasse da política urbana no Brasil. Petrópolis: Vozes, 2011. 
MARTINS, A. S.; LEITE, M. E. Análise do crescimento das favelas da cidade de Montes Claros MG por imagens de alta resolução espacial. In: Anais XVII Simpósio Brasileiro de Sensoriamento Remoto - SBSR. João Pessoa: INPE, 2015. p. 3715-3721. Disponível em: <http://www.dsr.inpe.br/sbsr2015/files/p0730.pdf> . Acesso em: 20 jun. 2015.

MASCARÓ, J. L. Infra-estrutura urbana. Porto Alegre: Masquatro Editora, 2005. 207p.

NOVO, E. M. L. M. Sensoriamento Remoto: Princípios e Aplicações. São Paulo: Blucher, 2008.

PANGEA. Programa CATA-AÇÃO. Diretrizes para o desenvolvimento socioambiental do bairro de Canabrava. Salvador: PANGEA, 2010.

ROSA, R. Introdução ao sensoriamento remoto. Uberlândia: UFU, 2007.

SANTOS, E.; PINHO, J. A. G. de; MORAES, L. R. S.; Fischer, T. (Org.). O Caminho das Águas em Salvador: Bacias Hidrográficas, Bairros e Fontes. Salvador: CIAGS/UFBA; SEMA, 2010. 486 p.

SOUZA, R. G. V. de. A expansão urbana da região metropolitana de Belo Horizonte e suas implicações para a redistribuição espacial da população: o caso do município de Nova Lima 1991/2000. 2005. 94 f. Dissertação (Mestrado) - Faculdade de Ciências Econômicas, Universidade Federal de Minas Gerais, Belo Horizonte, 2005.

VOLPE, L. L.; LOMBARDO, M. A. A análise do uso da terra no entorno do trecho oeste do Rodoanel Mario Covas na cidade de São Paulo por meio de técnicas de Sensoriamento Remoto. In: Revista do Departamento de Geografia, Universidade de São Paulo, v. 21, p. 23-43, 2011. 
Disponível em: <http://www.revistas.usp.br/rdg/article/view/47229/50965>. Acesso em: 20 jun. 2015.

Revista Eletrônica: Tempo - Técnica - Território, V.6, N.1 (2015), 49:72 ISSN: 2177-4366 